\title{
Influence of Secondary and Associated Conditions on the Health Status of Persons with Stroke-Related Paralysis: Cross Sectional Analysis of the National Paralysis Survey
}

\author{
Alicia Dixon-Ibarra*1, Michelle Odden², Gloria Krahn ${ }^{3}$ and Karen Hooker ${ }^{3}$ \\ ${ }^{1}$ Oregon State University Corvallis, USA \\ ${ }^{2}$ OR College of Public Health and Human Sciences, USA \\ ${ }^{3}$ Gerontology and Epidemiology programs, USA
}

Submission: September 24, 2017; Published: September 27, 2017

*Corresponding author: Alicia Dixon-Ibarra, Oregon State University Corvallis,118M Milam Hall, Corvallis, USA, Tel: (814)934-0757,

Email:Alicia.dixon-ibarra@oregonstate.edu

\begin{abstract}
Objective: To investigate the relationship between secondary (preventable) and associated (sequelae of stroke) conditions and poor health status among US adults with stroke-related paralysis.
\end{abstract}

Design: A cross sectional epidemiological study was conducted using the National Paralysis Survey data. This survey is a random digit-dial survey of over 70,000 households, conducted in 2012-2013, which examines the health of persons with paralysis.

Setting: National representative population of persons with paralysis in the United States.

Participants: Adults with stroke-related paralysis ( $\mathrm{n}=446)$

Main outcome and Measures: Descriptive and weighted logistic regression analyses determined associations between poor health status (i.e., fair to poor reported health) and secondary/associated conditions (i.e., contractures, injury, abnormal muscle movement, pain, sleep disturbances, urinary tract infections, autonomic dysreflexia, and sexual dysfunction) among persons with stroke-related paralysis.

Results: Sleep disturbances (61\%), pain (54\%), abnormal muscle movement (49\%), and urinary tract infections (45\%) had the highest prevalence. All but abnormal muscle movement $(\mathrm{p}=0.08)$ were associated with poor health status after controlling for covariates (i.e., age, sex, race, education, marital status, and severity of paralysis). After controlling for covariates and all other conditions, sleep disturbances (OR = 3.26; $95 \% \mathrm{CI}, 1.63-6.51 ; \mathrm{p}<0.001)$ and urinary tract infections (OR= 2.96; 95\% CI, 1.53-5.73; $\mathrm{p}<0.001)$ remained associated with poor health status.

Conclusion: Sleep disturbances, urinary tract infections, and pain are among the most prevalent to negatively impact health status. Rehabilitation and health promotion activities targeting the prevention of secondary conditions and amelioration of associated conditions could increase the health-related quality of life of this population.

Keywords: Stroke; Health Status; Secondary; Associated Conditions

Abbreviations: NPS: National Paralysis Survey; UTI: Urinary Tract Infection; CAUTI: Catheterization Associated Urinary Tract Infection

\section{Introduction}

Persons who experience paralysis following stroke frequently also experience other conditions related to their primary condition. Prevention of the frequency or intensity of these secondary and associated conditions can improve health and quality of life. Secondary and associated conditions are physical, mental, and social disorders resulting directly or indirectly from a primary disability [1-3]. Secondary conditions (e.g., pain, urinary tract infections, pressure sores) are considered preventable while associated conditions (e.g., contractures, autonomic dysreflexia, sexual dysfunction) may be mitigated. The objective of this cross-sectional study was to determine the relationship between secondary and associated conditions and poor health status among US adults with stroke-related paralysis. It is hypothesized that certain conditions (i.e., pain and sleep disturbances) are more strongly associated with poor health status than other secondary 
and associated conditions and should be targeted in rehabilitation and health promotion. Pain and sleep disturbances are common in this population and influence mental states and overall health outcomes $[4,5]$.

\section{Methods}

A cross sectional study was conducted using the National Paralysis Survey (NPS). The NPS was developed by the Centers for Disease Control and Prevention with the Christopher and Dana Reeve Foundation. This population-based telephone survey conducted in 2012-2013 contacted70, 458 households to identify 1,305 households who had at least one person with paralysis. It was cognitively-tested and pilot-tested before field implementation [6]. Participants who responded 'yes' to having "difficulty in moving the upper or lower extremities" and identified 'stroke' as the condition or health problem that caused difficulty in movement were included in the study.

Health status was assessed with the self-report question "In the past 30 days, would you say your general health is: excellent, very good, good, fair, or poor," and was coded dichotomously (good-excellent v. fair-poor). The NPS asked participants about presence of secondary and associated conditions resulting from their primary disability (yes/no). The conditions utilized in this analysis included: contractures (i.e., loss of joint motion), injury as a result of loss of sensation (i.e., cut, burn, broken bone), abnormal muscle movement (i.e., spasticity, uncontrolled jerky movement, or low muscle tone), pain, sleep disturbances (i.e., difficulty falling asleep, staying asleep, staying awake during the day, waking up early), urinary tract infections (UTI), autonomic dysreflexia (i.e., high blood pressure from overstimulation to the nervous system), and difficulty with sexual function. Demographic and paralysis specific variables included in analyses were age $(<45,45-54$, 55-64, >65 years), sex (male, female), race (white, non-white), education (<high school, high school graduate, college graduate), marital status (single, married, separated/divorced, widow), and severity of paralysis (difficulty bathing or dressing, difficulty remembering, difficulty performing errands). This study used deidentifiable data, which was exempt from institutional review.

Prevalence and confidence intervals (95\% CI) were calculated for demographics and secondary/associated conditions. Chisquare tests assessed differences among variables and health status. Logistic regression analyses were conducted using appropriate sample weights to correct for differential selection probabilities and adjust for non-coverage and non-response to determine the odds ratio of poor health status for each secondary/ associated condition in independent models and in one combined model with all conditions included. Models were controlled for age, sex, race, education, marital status, and severity of paralysis (i.e., difficulty bathing/ dressing) using State version 13.

\section{Results}

The overall survey response rate was $21 \%$, with 446 persons with stroke-related paralysis identified from the NPS. Poor health status was reported by $60 \%$ of persons with stroke-related paralysis (Table 1). Poor health status was most prevalent among adults aged 55-64 years (69.3\%), female (61.7\%), white $(60.4 \%)$, single (67.9\%), and less than high school education (62.5\%). There were significant differences by health status in the distribution of age $(p=0.03)$ and severity of paralysis variables $(p<0.001)$ (Table 1). The following secondary/associated conditions were most prevalent, ranging from $40-60 \%$ of the population: pain, sleep disturbances, urinary tract infections, and abnormal muscle movement. All were associated with health status, except sexual dysfunction, which was marginally statistically significant $(p=0.06)$ (Table 1). Logistic regression analyses showed all but abnormal muscle movement $(\mathrm{p}=0.08)$ were associated with poor health status after controlling for covariates (Table 2). In a combined model including all covariates and secondary/ associated conditions, only sleep disturbances and UTI remained associated with poor health status (sleep OR $=3.26$; 95\% CI, 1.636.51; $\mathrm{p}<0.001$; UTI OR= 2.96; 95\% CI, 1.53-5.73; $\mathrm{p}<0.001$ ).

Table 1: Association between Secondary Conditions and Health Status Among Persons with Stroke ( $n=446)$, National Paralysis Survey, 20122013.

\begin{tabular}{|c|c|c|c|c|}
\hline & Category Total,\%a & $\begin{array}{c}\text { Good-Excellent Health } \\
\text { Status, \% }\end{array}$ & $\begin{array}{c}\text { Fair-Poor Health } \\
\text { Status,\% }\end{array}$ & P value \\
\hline All respondents $(n=446)$ & & 40.0 & 60.0 & \\
\hline \multicolumn{5}{|l|}{ Age (years), $(n=446)$} \\
\hline$<45$ & 6.3 & 53.6 & 46.2 & \multirow{4}{*}{$\mathrm{p}=0.03$} \\
\hline $45-54$ & 11.2 & 33.3 & 66.7 & \\
\hline $55-64$ & 26.0 & 30.7 & 69.3 & \\
\hline$>65$ & 56.5 & 44.0 & 56.0 & \\
\hline \multicolumn{5}{|l|}{ Sex, $(n=442)^{b}$} \\
\hline Male & 49.5 & 41.7 & 58.3 & \multirow{2}{*}{$\mathrm{p}=0.06$} \\
\hline Female & 50.4 & 38.3 & 61.7 & \\
\hline \multicolumn{5}{|l|}{ Race, $(n=431)^{b}$} \\
\hline White & 70.5 & 39.6 & 60.4 & \multirow{2}{*}{$\mathrm{p}=0.81$} \\
\hline Non-white & 29.5 & 40.8 & 59.2 & \\
\hline
\end{tabular}




\section{Juniper Online Journal of Public Health}

\begin{tabular}{|c|c|c|c|c|}
\hline Marital Status, $(n=444)^{b}$ & & & & \\
\hline Single & 18.5 & 32.1 & 67.9 & \multirow{2}{*}{$\mathrm{p}=0.20$} \\
\hline Married & 43.2 & 40.8 & 59.2 & \\
\hline Separated/divorced & 21.2 & 47.8 & 52.2 & \\
\hline Widow & 17.1 & 38.1 & 61.8 & \\
\hline \multicolumn{5}{|l|}{ Education, $(\mathrm{n}=427)^{\mathrm{b}}$} \\
\hline Less than high school & 19.0 & 37.5 & 62.5 & \multirow{3}{*}{$\mathrm{p}=0.20$} \\
\hline High school grad & 60.1 & 38.4 & 61.7 & \\
\hline College grad & 20.4 & 48.8 & 51.2 & \\
\hline \multicolumn{5}{|l|}{ Severity of limitation } \\
\hline \multicolumn{5}{|l|}{$\begin{array}{l}\text { Difficulty bathing/dressing, } \\
\qquad(\mathrm{n}=445)^{\mathrm{b}}\end{array}$} \\
\hline Yes & 59.3 & 32.3 & 67.7 & $\mathrm{p}<0.001$ \\
\hline \multicolumn{5}{|l|}{$\begin{array}{l}\text { Difficulty remembering, } \\
(\mathrm{n}=440) \mathrm{b}\end{array}$} \\
\hline Yes & 54.5 & 28.5 & 71.5 & $\mathrm{p}<0.001$ \\
\hline \multicolumn{5}{|l|}{$\begin{array}{l}\text { Difficulty performing } \\
\text { errands, }(\mathrm{n}=442)^{\mathrm{b}}\end{array}$} \\
\hline Yes & 68.3 & 34.0 & 66.0 & $\mathrm{p}<0.001$ \\
\hline \multicolumn{5}{|l|}{ Secondary Conditions } \\
\hline Contractures, $(n=425)^{b}$ & 35.5 & 27.8 & 72.2 & $\mathrm{p}<0.001$ \\
\hline Injury, $(\mathrm{n}=442)^{\mathrm{b}}$ & 18.1 & 26.3 & 73.8 & $\mathrm{p}=0.005$ \\
\hline $\begin{array}{l}\text { Abnormal movement, } \\
\qquad(\mathrm{n}=432)^{\mathrm{b}}\end{array}$ & 49.3 & 34.9 & 65.1 & $\mathrm{p}=0.02$ \\
\hline Pain, $(\mathrm{n}=435)^{\mathrm{b}}$ & 54.3 & 30.9 & 69.1 & $\mathrm{p}<0.001$ \\
\hline $\begin{array}{l}\text { Sleep disturbances, } \\
(\mathrm{n}=436)^{\mathrm{b}}\end{array}$ & 60.8 & 31.6 & 68.4 & $\mathrm{p}<0.001$ \\
\hline $\begin{array}{l}\text { Urinary tract infection, } \\
\qquad(\mathrm{n}=430)^{\mathrm{b}}\end{array}$ & 44.9 & 30.2 & 69.8 & $\mathrm{p}<0.001$ \\
\hline $\begin{array}{l}\text { Autonomic dysreflexia, } \\
\qquad(\mathrm{n}=389)^{\mathrm{b}}\end{array}$ & 26.7 & 30.0 & 70.0 & $\mathrm{p}=0.005$ \\
\hline $\begin{array}{l}\text { Sexual dysfunction, } \\
(\mathrm{n}=384)^{\mathrm{b}}\end{array}$ & 29.9 & 32.5 & 67.5 & $\mathrm{p}=0.06$ \\
\hline
\end{tabular}

a May not total $100 \%$ because of rounding.

bNumber of participants is reduced because of list-wise deletion (i.e., any participants with missing data were excluded).

$c X^{2}$ test used to calculate $P$ values.

Table 2: Multivariable Logistic Regression Analysis, Association between Secondary/ Associated Conditions and Poor Health Status Among Stroke-Related Paralysis ( $\mathrm{n}=446$ ), National Paralysis Survey, 2012-2013.

\begin{tabular}{|c|c|c|c|}
\hline & Crude OR (95\% CI) & Model 1 Adjusted 0R (95\% CI) & Model 2 Adjusted OR (95\% CI) $^{\mathbf{b}}$ \\
\hline Contractures & $2.20(1.31-3.69)$ & $2.03(1.14-3.61)$ & $1.19(0.60-2.35)$ \\
\hline Injury & $3.04(1.61-5.72)$ & $2.32(1.10-4.90)$ & $1.75(0.73-4.23)$ \\
\hline Abnormal movement & $1.87(1.16-2.00)$ & $1.58(0.94-2.67)$ & $0.65(0.33-1.30)$ \\
\hline Pain & $2.45(1.52-3.95)$ & $2.17(1.26-3.76)$ & $1.11(0.57-2.16)$ \\
\hline Sleep disturbances & $2.52(1.55-4.09)$ & $2.70(1.58-4.63)$ & $3.26(1.63-6.52)$ \\
\hline UTI & $2.86(1.78-4.61)$ & $2.85(1.60-5.08)$ & $2.96(1.53-5.73)$ \\
\hline Autonomic dysreflexia & $2.07(1.17-3.67)$ & $2.02(1.05-3.89)$ & $1.65(0.74-3.52)$ \\
\hline Sexual Dysfunction & $1.61(0.93-2.81)$ & $2.02(1.03-3.96)$ & $1.60(0.73-3.52)$ \\
\hline
\end{tabular}

aModel 1 adjusted for age, sex, race, education, marital status, and severity of paralysis (i.e., difficulty bathing/dressing).

b Model 2 adjusted for model 1 variables and other secondary/associated conditions. 


\section{Discussion}

As hypothesized sleep disturbances and pain were among the most prevalent to negatively impact health status. Findings also indicate that UTIs were highly prevalent and strongly associated to poor health status in this population. This preventable secondary condition, although common in persons with paralysis, is influencing health status of individuals post stroke.

Sleep disturbances occur in more than $50 \%$ of stroke patients [4]. The presence and severity of sleep disturbances are typically realized once patients return to their daily lives [7], making post-discharge involvement critical. In conjunction with medical treatment, health promotion activities can enhance awareness of opportunities for improved health through recognizing sources of pain and severe sleep problems and encouraging on-going communication providers.

Pain is associated with depression, cognitive dysfunction, and decreased quality of life [5]. It is often under-recognized, undertreated, and persons with stroke are often inadequately educated about their post-stroke pain (5). Although pain was not associated with health status after adjusting for all conditions, this may have been due to the co-occurrence of pain with other conditions. Pain is subjective, and therefore susceptible to measurement error compared with other conditions such as UTI.

UTIs are also a common complication in stroke patients [8]. Catheterization-associated urinary tract infection (CAUTI) is caused by prolonged use of a catheter. CAUTI has been addressed by multiple national organizations including the Centers for Disease Control and Prevention, which has developed guidelines for the prevention of CAUTI [9]. The implementation of these guidelines in healthcare facilities, among caregivers and persons with stroke-related paralysis could reduce this preventable secondary condition and improve health status.

\section{Study Limitations}

This study can be generalized to a specific population of individuals with stroke in the United States, specifically persons who initially reported 'difficulty in moving the upper or lower extremities.' There are limitations using secondary data sources. The NPS was designed to assess a broader population of persons with paralysis and not specifically stroke, so study findings are weighted to a broader national population of paralysis. Moreover, the study asked participants if they 'ever' had the secondary/ associated condition. Resulting, some persons in the study may not have had the condition at the time of the study. Further sexual dysfunction and autonomic dysreflexia had approximately 12$13 \%$ missing data, compared to the other exposures, outcomes, and covariates that had less than $5 \%$ missing. This may have affected the individual adjusted models including these conditions and the concurrent secondary and associated condition adjusted model.

\section{Conclusion}

Rehabilitation for individuals with stroke-related paralysis should emphasize self-care and self-monitoring, pain management, healthy lifestyles, and promoting individual control over health [10]. Secondary conditions should be a focus of health promotion activities and complement rehabilitation and medical intervention in order for individuals' post-stroke to reach an optimal state of health.

\section{References}

1. Krahn GL, Hammond L, Turner AA (2006) cascade of disparities: Health and health care access for people with intellectual disabilities. Mental Retardation and Developmental Disabilities Research Reviews 12(1): 70-82.

2. Simeonsson RJ, McDevitt LN (1999) Issues in disability \& health: The role of secondary conditions \& quality of life. NC Office on Disability and Health.

3. Turk MA (2006) Secondary conditions and disability. Paper presented at the Workshop on Disability in America: A New Look, PP. 185-193.

4. Hermann DM, Bassetti CL (2016) Role of sleep-disordered breathing and sleep-wake disturbances for stroke and stroke recovery. Neurology 87(13): 1407-1416.

5. Harrison RA, Field TS (2015) Post stroke pain: Identification, assessment, and therapy. Cerebro vascular Diseases 39(3-4): 190-201.

6. Fox MH, Krahn GL, Sinclair LB, Cahill A (2015) Using the international classification of functioning, disability and health to expand understanding of paralysis in the united states through improved surveillance. Disability and Health Journal 8(3): 457-463.

7. Bassetti CL, Hermann DM (2011) Sleep and stroke. Sleep Disorders 99: 1052-1069.

8. Aroor S, Branson P, Turner A, Lee J (2015) Prevention of catheter associated urinary tract infections in stroke patients (P1. 009). Neurology 84(14): 1-9

9. Centers for Disease Control and Prevention (CDC) (2015) Catheterassociated urinary tract infections (CAUTI).

10. Stuifbergen AK, Gordon D, Clark AP (1998) Health promotion: A complementary strategy for stroke rehabilitation. Topics in Stroke Rehabilitation 5(2): 11. 
This work is licensed under Creative Commons Attribution 4.0 Licens

DOI: 10.19080/JOJPH.2017.02.555588
Your next submission with Juniper Publishers will reach you the below assets

- Quality Editorial service

- Swift Peer Review

- Reprints availability

- E-prints Service

- Manuscript Podcast for convenient understanding

- Global attainment for your research

- Manuscript accessibility in different formats

( Pdf, E-pub, Full Text, Audio)

- Unceasing customer service

Track the below URL for one-step submission https://juniperpublishers.com/online-submission.php 